\title{
Evaluation of iron overload: dual-energy computed tomography versus magnetic resonance imaging
}

\author{
El-Sayed H Ibrahim*, Andrew W Bowman \\ From 17th Annual SCMR Scientific Sessions \\ New Orleans, LA, USA. 16-19 January 2014
}

\section{Background}

Iron toxicity is key factor for tissue damage in ironoverloaded patients, with induced heart failure as the main cause of death. T2*-weighted MRI has been established as the method of choice for evaluating iron-content with strong correlation with biopsy, where $\mathrm{T} 2^{*}<20 \mathrm{~ms}$ and $\mathrm{T} 2^{*}<10 \mathrm{~ms}$ at $1.5 \mathrm{~T}$ indicate iron overload and severe iron overload, respectively. Recently-introduced dualenergy CT (DECT) has the potential for evaluating iron overload without energy-dependent $\mathrm{CT}$ attenuation or tissue fat effects. The aim of this study is to investigate the performance of DECT for iron mapping in in-vitro scans of calibrated iron phantoms and compare results to MRI.

\section{Methods}

Ten 50-mL agarose phantoms(tubes) were created to mimic myocardial T1\&T2 with different iron contents:0-4.5 g. The phantoms were imaged on Siemens 1.5T-MRI and DECT scanners. A GRE MRI sequence was used with 12 -echoes ( $\mathrm{TE}=1-16 \mathrm{~ms}), 2.8 \mathrm{~mm}$ resolution, and $19 \mathrm{~s}$ scan-time. Two DECT scans were conducted with $80 / 140 \mathrm{kVp}$ and 100/140 kVp, $0.3 \mathrm{~mm}$ resolution, and $2 \mathrm{~s}$ scan-time. 2 -cm2 ROI's were used to measure average signal intensities in MRI and Hounsfield Units (HU) in CT. The values from MRI images were fitted to mono-exponential curves to measure T2* and $\mathrm{R} 2 *\left(=1 / \mathrm{T} 2^{*}\right)$. Correlation analysis was conducted between iron-content, $\mathrm{R}^{*}$, and $\mathrm{HU}$ values/differences/ ratios at different energies (the $120 \mathrm{kVp}$-image automatically calculated by the scanner). Two tubes had $\mathrm{T} 2 *=10 \mathrm{~ms}$ and $21 \mathrm{~ms}$, which were used to identify boundaries between different iron-overload categories.

\section{Results}

Figures 1 \&2 show the phantoms, T2*-map, CT images, plots of R2* and $\mathrm{HU}$ versus iron-content, T2* curves fitting, and DECT iron-map. T2* ranged from 6 $\mathrm{ms}$ to $36 \mathrm{~ms}$. There were strong correlations between iron-content and $\mathrm{R} 2 *$, HU values and $\mathrm{HU}$ differences at different energy levels $(r>0.95$ and $\mathrm{P}<0.0001)$. There were moderate correlations between iron-content and HU ratios (except 80/140) with $0.42<|\mathrm{r}|<$ 0.76 and $0.02<\mathrm{P}<0.2$. The $\mathrm{T} 2 *$ relaxation curves of the $21 \mathrm{~ms}$ and $10 \mathrm{~ms}$ tubes were used to differentiate between normal, overloaded, and severely-overloaded iron (Figure 1d). The HU values of these two tubes showed perfect linear relationships with energy-level (E) over diagnostic levels $80-140 \mathrm{kVp}: \mathrm{HU}=-0.29 \mathrm{E}$ +56.3 and $\mathrm{HU}=-0.76 \mathrm{E}+151.8$ for the $21 \mathrm{~ms}$ and 10 ms T2*-values. The resulting CT-map (Figure 2d) is used to identify three regions: normal, overloaded, and severely-overloaded iron.

\section{Conclusions}

DECT can be used for iron quantification with high accuracy similar to MRI, which might help in patient staging, independent of the energy level. New DECT scanners with low radiation-exposure, much shorter scan-time, and higher capability of measuring large iron-contents compared to MRI, may provide promising approach for evaluating myocardial iron overload.

\section{Funding}

N/A. 


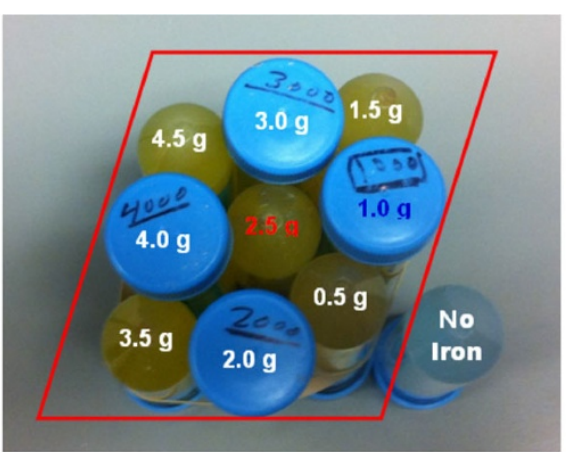

(a)

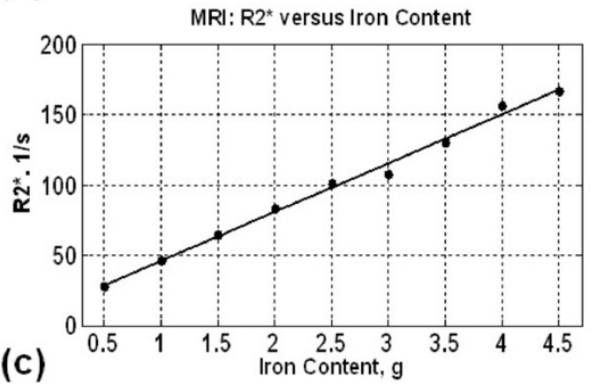

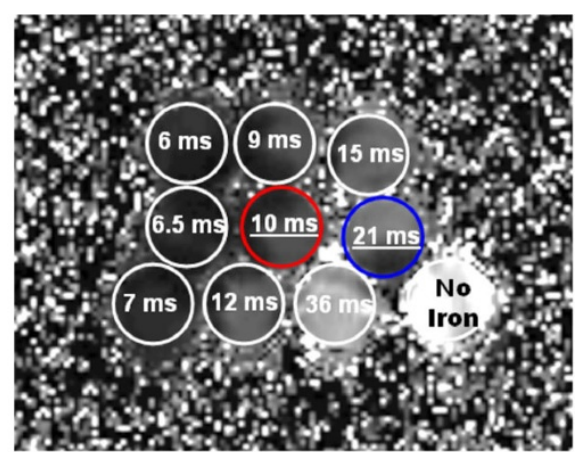

(b)

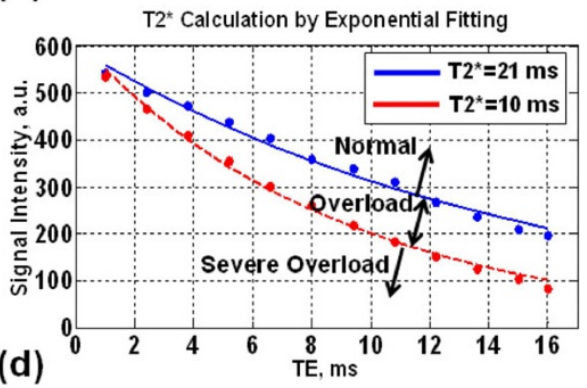

Figure 1 MRI Results. (a) Picture of the phantom with different iron contents (in grams) identified. (b) T2* map showing estimated T2* values for different tubes. (c) Linear relationship between iron content and $R 2^{*}\left(=1000 / T 2^{*}\right)$. (d) Exponential fittings of the T2* relaxation curves versus echo time (TE) for the tubes that resulted in T2* of $21 \mathrm{~ms}$ (blue) and $10 \mathrm{~ms}$ (red), which represent the boundaries for iron overload and severe iron overload, respectively. Three regions can be identified on this figure for relaxation curves from tissues with normal iron content (T2* $>21$ $\mathrm{ms})$, iron overload (10 ms $\left.<\mathrm{T} 2^{*}<21 \mathrm{~ms}\right)$, and severe iron overload $\left(\mathrm{T} 2^{*}<10 \mathrm{~ms}\right.$ ).

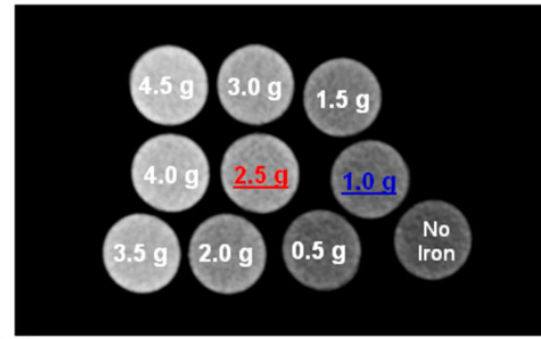

(a)

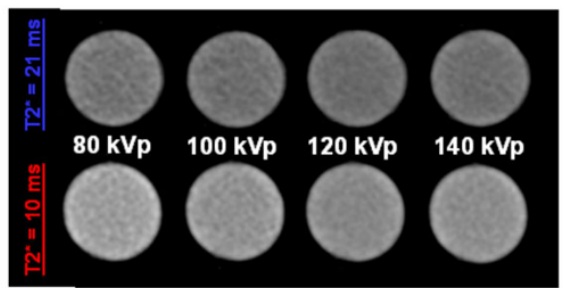

(c)

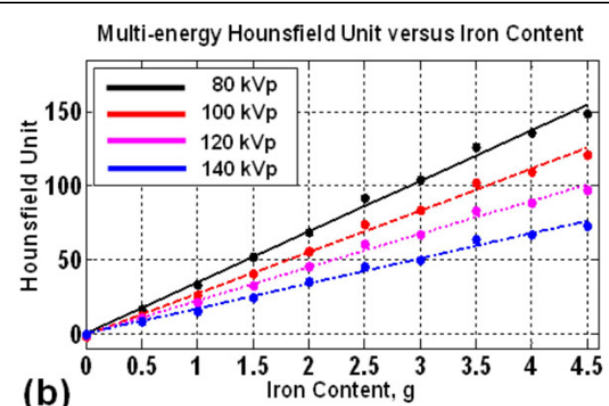

(b)

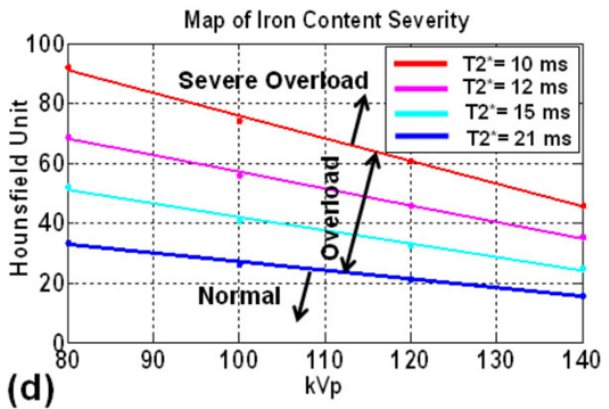

Figure 2 Dual-energy CT Results. (a) CT image of the phantom at one of the four acquired energies (100 kVp). (b) Relationships between Hounsfield unit and iron content at different energy levels (80, 100, 120, 140 kVp). (c) Sequence of CT images of the tubes that resulted in T2* values of $21 \mathrm{~ms}$ (top) and $10 \mathrm{~ms}$ (bottom), respectively, at different energy levels. (d) Linear relationships between Hounsfield unit and energy level for the iron tubes that resulted in T2* between $10 \mathrm{~ms}$ (red) and $21 \mathrm{~ms}$ (blue). The figure can be used as a map to identify the severity of iron overload based on the resulting Hounsfield unit and implemented kVp. Three regions can be identified on this map representing tissues with normal iron content (region below the blue line), iron overload (region between the blue and red lines), and severe iron overload (region above the red line). 
Published: 16 January 2014

doi:10.1186/1532-429X-16-S1-092

Cite this article as: Ibrahim and Bowman: Evaluation of iron overload: dual-energy computed tomography versus magnetic resonance imaging Journal of Cardiovascular Magnetic Resonance 2014 16(Suppl 1):O92.

Submit your next manuscript to BioMed Central and take full advantage of:

- Convenient online submission

- Thorough peer review

- No space constraints or color figure charges

- Immediate publication on acceptance

- Inclusion in PubMed, CAS, Scopus and Google Scholar

- Research which is freely available for redistribution

Submit your manuscript at www.biomedcentral.com/submit

() Biomed Central 